\title{
IMPACTOS SOCIOAMBIENTAIS DAS INDÚSTRIAS DA CAL, NO DISTRITO DE SOLEDADE DO MUNICÍPIO DE APODI - RN
}

\section{Luanna Lívia Gurgel \\ Graduada em Gestão Ambiental pela Universidade do Estado do Rio Grande do Norte - UERN luannagurgel@hotmail.com}

\author{
Jorge Luis de Oliveira Pinto Filho \\ Professor da Universidade do Estado do Rio Grande do Norte - UERN \\ jorgefilho-uern@bol.com.br
}

\section{RESUMO}

A atividade de produção da cal, incluída nas indústrias de minerais não-metálicos, tem como matéria-prima principal o calcário, sendo esse recurso de grande abundância na região da Chapada do Apodi, no Estado do Rio Grande do Norte. Este trabalho tem por objetivo descrever o processo produtivo da indústria da cal no Distrito de Soledade, localizado no município de Apodi - RN, bem como apontar os principais os impactos socioambientais dessa atividade. Os dados primários foram obtidos por meio de questionários aplicados com a população e as indústrias da cal da área de estudo. Em seguida, foram realizadas visitas in loco, com a finalidade de identificar os impactos socioambientais pelo método de avaliação de impacto: check-list. Verificou-se que a ocorrência do calcário é conhecida há muito tempo, tornando-se uma das principais atividades econômicas da região, sendo a principal fonte de renda e emprego para a comunidade que reside no Distrito de Soledade. No entanto, foi percebido que a atividade da cal é degradante, uma vez que além da exploração dos recursos naturais, como o calcário, há ainda a extração da vegetação nativa como fonte energética. Constatou também um quadro alarmante sobre as condições de trabalho das industriais da referida pesquisa, já que os trabalhadores não recebem nenhum tipo de treinamento em segurança, saúde e meio ambiente; não utilizam equipamentos de proteção individuais e; não possuem nas instalações das indústrias, banheiros, bebedouros ou refeitórios. Para tanto, aponta como solução para a problemática a adoção de políticas públicas sobre manejo florestal da caatinga; melhoria nas condições de trabalho e práticas ambientais das indústrias.

Palavras-chave: Calcário; Degradação ambiental; Extração mineral.

\section{SOCIAL AND ENVIRONMENTAL IMPACTS OF LIME MANUFACTURING IN THE DISTRICT OF THE CITY OF SOLEDADE APODI - RN}

\section{ABSTRACT}

The production of lime is included amongst the industries of non-metallic minerals, the main raw material being limestone, making use of the great wealth within the plateau of Apodi. This paper aims to describe the production process of the lime industry in the District of Soledade, in the city of Apodi - RN, and to identify the main environmental impacts of this activity. The primary data were obtained through questionnaires given to residents and industries of the lime of the study space. Site visits were carried out in order to identify the environmental impacts through the method of impact assessment, which is a check-list. It was found that the occurrence of limestone has been known for a long time, becoming one of the main economic activities in the region, being the main source of income and employment for the community residing in the District of Soledade. However, it was realized that the activity of mining lime is degrading because beyond the exploitation of natural resources, such as limestone, there is the extraction of native vegetation as an energy source. It also found an alarming picture of the working conditions of industrial research since workers do not receive any training in safety, health and environment, dangers of not using personal protective equipment, and that facilities of the industries have inadequate bathrooms, drinking or dining areas. As solution to the problem, it is recommended the adoption of public policies on forest caatinga, improvement in working conditions and environmental practices of the industries.

Keywords: Mining; limestone; environmental degradation.

Revista de Gestão Social e Ambiental - RGSA, São Paulo, v. 6, n. 1, p. 87-101, jan./abr. 2012. 


\section{INTRODUÇÃO}

As atividades humanas, as chamadas econômicas, são de grande importância para o setor da economia mundial, sendo também um dos setores que mais alteram o meio ambiente.

Atualmente, existe uma preocupação relacionada aos problemas que acarretam impactos ambientais, que podem variar de acordo com o tipo de indústria, matérias-primas utilizadas, produtos fabricados, substâncias produzidas e descartadas e do próprio processo de produção. Portanto, todo e qualquer processo de industrialização pode causar algum tipo de alteração no meio ambiente, que pode ser maléfica ou benéfica. Assim como toda atividade de exploração de recurso natural, a atividade caieira provoca impactos no meio ambiente, seja no que diz respeito à exploração de áreas naturais ou mesmo na geração de resíduos.

Percebe-se que essa atividade é uma das grandes geradoras de impactos ambientais, não havendo nenhuma preocupação com os danos relacionados ao meio ambiente, especificamente no que diz respeito ao uso sem controle dos recursos naturais, como a exploração do calcário.

Uma preocupação relevante é a retirada e o uso da madeira nativa que é utilizada como combustível para queima da cal, que resulta numa degradação ambiental, que, por sua vez, pode ocasionar a extinção de espécies da flora, e consequentemente da fauna, bem como a fuga de animais silvestres, que também pode ser atingida pelo ruído perturbador, além de alterar a qualidade do solo. Outra consequência resultante dessa atividade envolve os veículos que são utilizados para transporte da madeira e do produto final, que, em sua maioria, estão em péssimas condições. Em uma visão geral, os problemas ocasionados por essa atividade podem vir a prejudicar a qualidade de vida da população que ali reside.

A atividade da cal é de grande importância para o Distrito de Soledade, isto significa que essa atividade afeta os indicadores socioeconômicos relacionados à geração de renda para população, melhoria nas finanças do distrito, na estrutura física do local, contribuindo, portanto, com a redução da taxa de desemprego e da pobreza dessa comunidade.

É preciso enfatizar que essa atividade também apresenta impactos positivos, tais como, a migração da população para esse distrito, uma maior rentabilidade para esses habitantes, uma valorização dos terrenos próximos a essas indústrias e geração de empregos, resultando numa melhor qualidade de vida para a população do Distrito de Soledade.

Cabe salientar, no entanto, que a discussão acerca dos impactos socioambientais oriundos da atividade industrial, não está restrita apenas aos grandes empreendimentos. No Rio Grande do Norte, onde foi desenvolvida esta pesquisa, verificou-se que qualquer processo de industrialização, inclusive os que realizam a atividade da cal, carece de estudos técnicos e socioambientais. A questão que se pretende responder é a seguinte: quais os possíveis impactos ambientais resultantes da atividade caieira no município de Apodi - RN?

Sendo assim, este trabalho teve como principal objetivo, verificar o processo de extração, produção e transporte da atividade caieira no município de Apodi - RN, bem como apontar os principais impactos socioambientais dessa atividade. Os objetivos específicos foram: identificar o perfil social dos moradores do distrito de Soledade, Apodi - RN; verificar o perfil das empresas da atividade caieira; e apontar os principais impactos socioambientais da atividade caieira.

\section{REVISÃO DE LITERATURA}

\subsection{Avaliação dos impactos socioambientais das indústrias}

A contaminação do meio ambiente natural pelas indústrias teve início com a revolução industrial no século XIX, e dessa época em diante este problema teve um crescimento exponencial, provocando diversas catástrofes ambientais (Dias, 2006).

Revista de Gestão Social e Ambiental - RGSA, São Paulo, v. 6, n. 1, p. 87-101, jan./abr. 2012. 
Existe hoje uma crescente preocupação pela implantação de uma nova política que compatibilize o desenvolvimento socioeconômico com a manutenção da qualidade ambiental e da produtividade dos recursos naturais, modificando assim, o frequente quadro de degradação ambiental aqui existente, mantendo um ambiente saudável e obtendo o desenvolvimento desejado.

Para que se possa saber sobre o quadro de degradação é necessário que se faça um diagnóstico da indústria, com apresentação de um levantamento da situação real da organização, quanto ao seu potencial poluidor. Logo, todo e qualquer processo de industrialização pode causar algum tipo de alteração no meio ambiente, que pode ser maléfica ou benéfica.

A poluição industrial, que é uma alteração considerada maléfica, constitui-se de resíduos gerados nos processos industriais. Um dos principais efeitos da poluição industrial é a poluição do ar, que além dos componentes naturais, vêm apresentando grandes variações devido ao uso abusivo dos processos industriais. Derisio (1992, p. 78) define poluição do ar como:

A presença ou lançamento no ambiente atmosférico de substâncias em concentrações suficientes para interferir direta ou indiretamente na saúde, segurança, e bem estar do homem, ou no pleno uso e gozo de sua propriedade. Essa poluição é proveniente em sua maioria pela queima da madeira para cozimento de determinado produto. Que então já vem a causar outro tipo de impacto que é o desmatamento.

Essas concentrações na atmosfera podem causar mudança no padrão de qualidade do ar. Para Derisio (1992), padrão de qualidade do ar define legalmente um limite máximo para a concentração de um componente atmosférico, que garanta a proteção da saúde e do bem-estar das pessoas.

As fontes de poluição do ar podem ser fixas ou móveis. As fixas compreendem as caldeiras e fornos e as fontes móveis englobam os veículos que transportam o material ou produto final (Derisio, 1992).

Esses fatores podem causar danos na sociedade, pois o recurso ar tem um consumo contínuo e obrigatório, sendo essencial para os sentidos da visão, olfato e audição. Se inspirado com componentes alterados pode afetar a saúde, provocando doenças agudas ou até a morte, doenças nas alterações fisiológicas, dano no crescimento, doenças dermatológicas, cardiovasculares e irritação sensorial. Também causam efeitos estéticos, sendo um efeito visível, como poeira e fumaça, sujando imóveis, causando o escurecimento e os materiais, como o ataque químico direto ou indireto e a corrosão eletroquímica. A vegetação também sofre as consequências da poluição atmosférica, ficando sujeita a alterações no crescimento e produtividade da planta, que resultam em seu envelhecimento, descoloração, geralmente devido a disposição de partículas nas folhas (Almeida, 1999).

As medidas mitigadoras são destinadas a corrigir ou compensar impactos negativos, ou a reduzir a magnitude, ou ainda potencializar impactos positivos. Para cada um dos impactos verificados no projeto, devem-se identificar os esquemas ou os mecanismos capazes de cumprir essa função, avaliando-se sua eficiência e eficácia, bem como definir os responsáveis pela sua implantação (Philippi Jr e Alves, 2005).

Contudo, algumas medidas mitigadoras devem ser estabelecidas onde o ambiente afetado pela ação humana possa, em certa medida, ser recuperado, mediante ações voltadas para essa finalidade, envolvendo medidas de melhoria do meio físico, a fim que restabeleça a vegetação e a qualidade do solo, além de medidas de manejo dos elementos bióticos do ecossistema.

Como todo processo produtivo, as indústrias necessitam de um mínimo de equipamentos para alcançar a produtividade ideal, visando tanto a segurança do trabalhador quanto a rentabilidade da referida atividade (Lora, 2002).

Nas sociedades urbano-industriais são necessárias abordagens relacionadas aos processos de produção e consumo, bem como de saúde e meio ambiente. As preocupações e olhares sobre a 
relação entre trabalho e saúde, contudo, remontam há muitos séculos, desde a antiguidade até hoje (Minayo et al, 2000).

A questão específica da saúde e segurança do trabalho ganhou impulso no século XIX, principalmente na Inglaterra, devido aos avanços sociais da revolução industrial, onde as jornadas de trabalho e as atividades eram intensas. No entanto, graças a divisão do trabalho e a simplificação das tarefas a qualidade do trabalho foi favorecida (Santana, 2006).

O caráter preventivo da higiene ocupacional foi aprimorado com a antecipação, ao reconhecimento e ao controle dos riscos ambientais tais como contato com substâncias químicas, gases, vapores, poeiras, fumaças, ruído, vibrações, temperaturas extremas e iluminação, e estresses originados no ambiente de trabalho ou proveniente deste, que podem causar doenças, comprometimento na saúde e do bem-estar, ou desconforto entre os trabalhadores e membros da comunidade. Tudo irá depender do limite de exposição ocupacional, referente à jornada de trabalho (Silva et al., 2007).

A natureza das agressões à saúde do trabalhador depende, basicamente, das condições materiais e ambientais do trabalho e da organização do trabalho em si, como a hierarquia e divisão do trabalho, intensidade e velocidade do processo, trabalho fragmentado e repetitivo, conteúdo do trabalho, regime de turnos, tensão, monotonia, pressão do tempo, relações coercivas, horas extras, etc. (Déjours 1987, apud Minayo et al, 2000).

A Associação Americana de Higienistas Industriais (AIHA) (2009) define a higiene industrial, ocupacional ou do trabalho como sendo a ciência e arte dedicadas à antecipação, ao reconhecimento, avaliação e controle desses fatores ou estresses ambientais que podem causar doenças, alterações na saúde ou desconforto significativo entre os trabalhadores ou entre os residentes da comunidade.

Para Minayo et al (2000), as empresas devem buscar uma atenção integral, com ações curativas e preventivas, obedecendo ao princípio de que não é eticamente admissível, nem tecnicamente correto atender e tratar um trabalhador doente ou acidentado do trabalho, sem tentar mudar as condições geradoras do problema, de modo a evitar sua repetição.

Podemos constatar na Lei de $\mathrm{n}^{\circ}$ 6.367, de 19 de outubro de 1976, que dispõe sobre o seguro de acidentes de trabalho, no seu artigo $2^{\circ}$ que conceitua acidente de trabalho, "[...]como aquele que ocorre pelo exercício de trabalho a serviço da empresa, provocando lesão corporal ou perturbação funcional que cause a morte, ou perda, ou redução, permanente ou temporária, da capacidade para o trabalho" (Brasil, 2009).

Não é comum nas empresas, o treinamento que inclua o desempenho da tarefa com segurança. Nem mesmo a promoção de ações educativas que propiciem hábitos saudáveis. A atividade de prevenção pode e deve estar sempre presente nas atividades acessórias de produção.

Portanto, todo processo produtivo, quer pelas características da maquinaria, quer pelas características dos materiais empregados, de alguma forma, ainda que minimamente, oferece oportunidade de risco aos trabalhadores. Compete então, ao gestor tomar todas as providências cabíveis ao estabelecimento das medidas necessárias à proteção desses trabalhadores (Barbosa Filho, 2001).

\section{MATERIAL E METÓDOS}

\subsection{Classificação da pesquisa}

Baseado em Gil (2006), este estudo classifica-se de acordo com a sua finalidade como exploratório. Quanto aos meios utilizados, essa pesquisa enquadra-se como estudo de campo e bibliográfico.

Várias condições foram observadas nas caieiras, principalmente a análise de percepção dos trabalhadores quanto às consequências do trabalho ao processo saúde-doença.

Revista de Gestão Social e Ambiental - RGSA, São Paulo, v. 6, n. 1, p. 87-101, jan./abr. 2012. 


\subsection{Procedimentos de pesquisa}

Para efeito de realização desse estudo, os dados coletados foram por meio de procedimentos metodológicos do tipo estudo bibliográfico, documental e coletas de dados em campo, junto à população e aos funcionários das indústrias da amostra da pesquisa.

As bases conceituais deste estudo foram realizadas por meio de uma fundamentação teórica, tendo como base livros e artigos da internet e das bibliotecas da UERN, UFERSA e UNP relacionados aos impactos ambientais, a degradação ambiental e a caracterização da atividade de produção da cal. Bem como, o diagnóstico das características físicas e bióticas do município de Apodi - RN.

Foram realizadas visitas a órgãos, tais como a Prefeitura Municipal de Apodi, mais especificamente a Secretaria Municipal de Saúde, o Instituto de Desenvolvimento Econômico e Meio Ambiente do Rio Grande do Norte (IDEMA) e o Instituto Brasileiro do Meio Ambiente e dos Recursos Naturais Renováveis (Ibama) com a finalidade de obter informações acerca da quantidade de indústrias da cal e se as mesmas são licenciadas. Vale salientar, que também foi visitado o Serviço Brasileiro de Apoio às Micro e Pequenas Empresas (Sebrae) com a finalidade de verificar o porte das indústrias.

\subsection{Obtenção de dados em campo e amostragem}

Para concretização desse estudo, os dados de campo foram obtidos por meio da aplicação de questionários nas próprias indústrias caieiras. Paralelamente, foram efetuadas diversas visitas preliminares ao Distrito de Soledade.

\subsubsection{Indústrias da cal}

Nesta fase, foi identificado um total de 15 indústrias da atividade caieira que estão em funcionamento. Optou-se por aplicar um questionário semiestruturado, contendo questões abertas e fechadas. Esses questionários foram aplicados em todas as unidades de fabricação da cal identificados, sendo respondidos pelos próprios empresários e pelos gerentes.

\section{RESULTADOS E DISCUSSÃO}

A produção da cal tem como matéria-prima principal o calcário, sendo esse recurso de grande abundância na região da Chapada do Apodi. A ocorrência do calcário é conhecida há muito tempo, tornando-se assim uma das principais atividades econômicas da região. Observa-se na (Figura 1) a área de extração do calcário para a produção da cal.

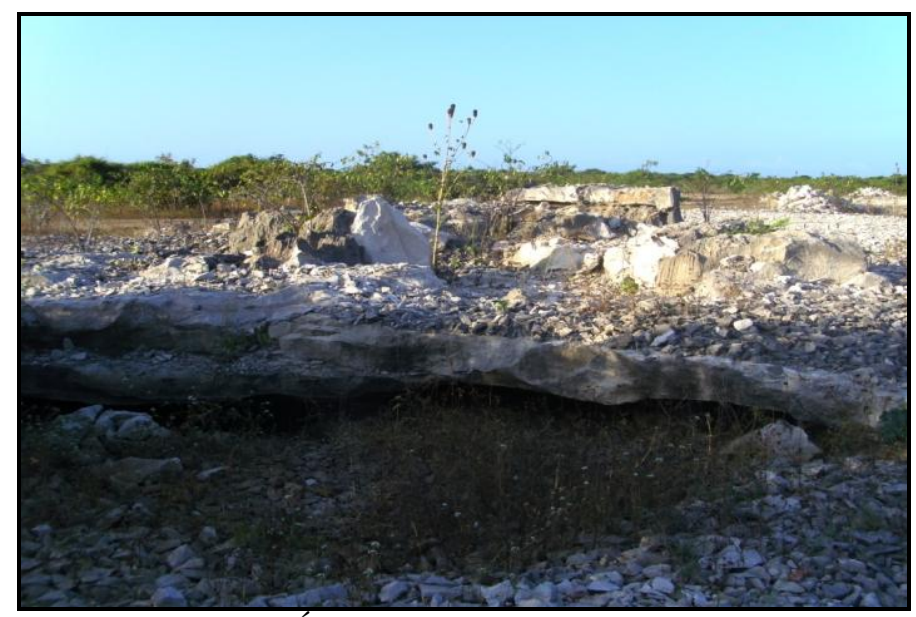

Figura 1: Área de extração do calcário, 2009.

Fonte: os autores. 
No tocante ao perfil das indústria da Cal do distrito de Soledade, Apodi - RN, verificou-se que possuem média de 25 a 40 funcionários, sendo assim classificada como industria de pequeno porte conforme classificação do Sebrae.

É importante destacar também, nesse momento, a quantidade de empregos indiretos gerados nesse processo, sendo um valor médio situado entre 30 a 50 por indústria. Vale mencionar que esses trabalhadores estão relacionados, principalmente, com a atividade de transporte da fonte energética, nesse caso especifico, a vegetação, bem como o produto final.

Com relação a quantidade da Cal produzida mensal pelas industrias de Soledade, constatou que não existe um valor fixo, já que essa demanda depende diretamente de pedidos feitos pelos consumidores.

Vale salientar que a indústria da Cal, mesmo sendo uma das mais antigas do Município de Apodi - RN, apresenta um modelo bastante arcaico, tendo como características a produção de forma artesanal e o desinteresse com a qualidade do ambiente e com a integridade física do trabalhador, como ilustra a Figura 2.

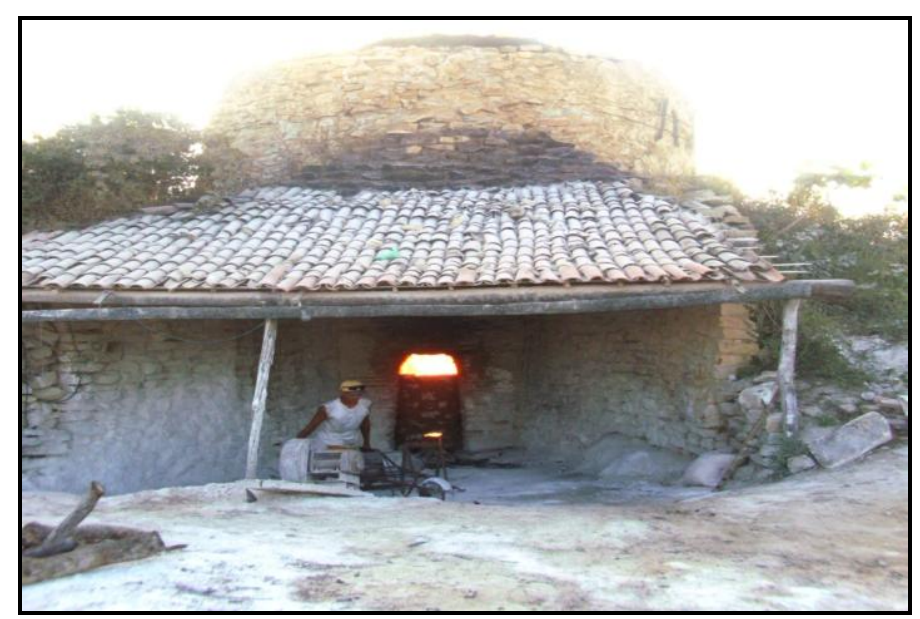

Figura 2: Forno da atividade caieira, 2009.

Fonte: os autores.

Ainda corroborando o processo de produção da cal de forma artesanal, observa-se na Figura 3 que $(60 \%)$ da extração do calcário é realizada de forma manualmente, com auxílio apenas de marretas e/ou picaretas.

Em relação ao uso manual e de explosivo, (40\%) dos produtores alegaram usar essa ferramenta como processo de produção da cal. Cabe mencionar que os responsáveis por essas indústrias apontam que adotam essa ferramenta por facilitar o processo, já que acelera toda a extração e produção do calcário.

É importante destacar que por mais pequena que seja a explosão, esse ato gera algumas consequências para os trabalhadores como dores de cabeça e diminuição de audição (como surdez temporária ou definitiva), bem como implicações ambientais, tais como fuga e o desaparecimento de espécies da fauna.

Evidenciando os possíveis danos aos trabalhadores da indústria da cal merece destaque a sua intensa jornada de trabalho de exposição aos raios solares, fazendo com que acarrete diversas consequências para a saúde desses trabalhadores, tais como desidratação, erupção da pele, câimbras de calor, catarata, conjuntivite e câncer de pele.

Vale salientar, que as consequências da extração do calcário não se restringem apenas a questão de saúde do trabalhador. Sendo assim, elenca também danos ambientais da seguinte ordem: modificação do perfil topográfico do terreno, desconfiguração da paisagem e poluição visual. 


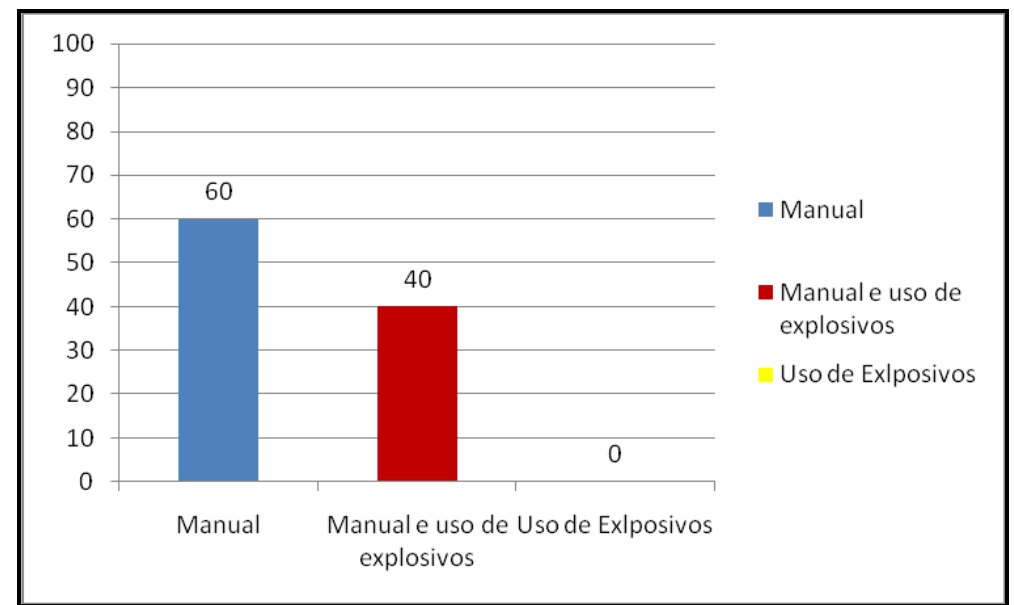

Figura 3: Como a extração do calcário é realizada na atividade da cal - 2009.

Fonte: dados da pesquisa.

Outro ponto que merece destaque neste estudo refere-se à fonte energética utilizada pelas indústrias da atividade da cal. Com isso, no decorrer da pesquisa, constatou-se que $100 \%$ dos produtores da cal da área de estudo utilizam a lenha como fonte de energia (Figura 4).

Com base nesta informação, a extração da lenha vem causar a degradação no bioma caatinga, cenário esse que pode ser mais drástico, em razão da extinção de algumas espécies, bem como pela fuga da fauna. Vale ressaltar, nesse momento de discussão, que a extração da lenha é uma das atividades mais incentivadoras do processo de desertificação no estado do Rio Grande do Norte. Evidenciando tal informação, Vianna (2006) aponta que os setores cerâmicos, da panificação e da cal do RN transformam em cinzas 175 mil metros cúbicos de lenha, por mês.

Somado a esse fator supracitado, existem as características físicas e bióticas da área de estudo como aliados na construção de um cenário futuro de uma Área Susceptível à Desertificação, uma vez que Idema (2003) aponta que o Município de Apodi - RN apresenta um clima caracterizado por ser muito quente e semiárido.

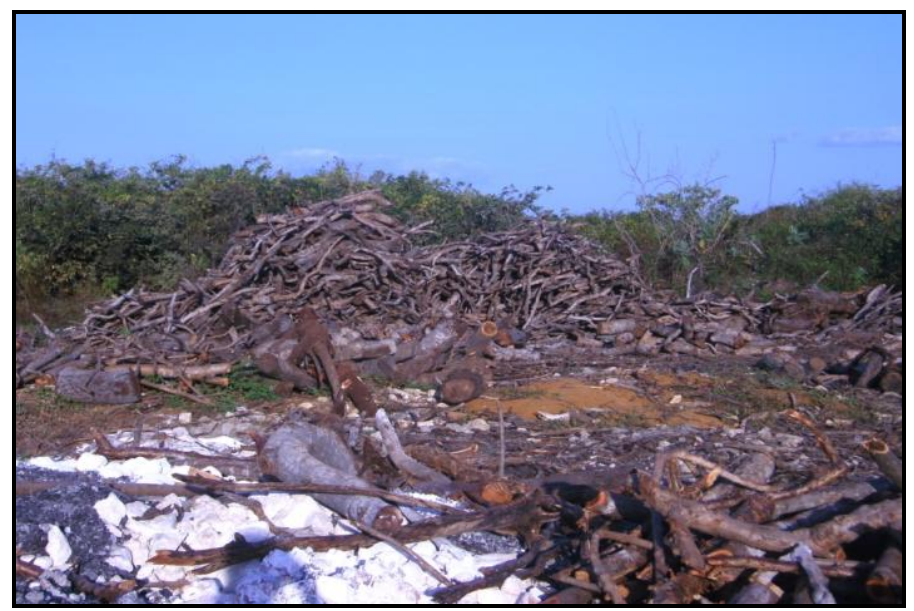

Figura 04: Lenha, principal fonte de energia, 2009.

Fonte: os autores.

Quando perguntado aos responsáveis pelas indústrias de Cal de Soledade sobre qual o tipo de lenha utilizada no processo produto, a resposta foi unâmine, todos responderam que utilizam a poda do cajueiro ou a casca da castanha como fonte energética, sendo esses materiais os únicos liberados pelo órgão licenciador do nosso estado, nesse caso o IDEMA. Todavia, verifica-se que tal informação é controversa, já que, como foi ilustrado na Figura 4, o recurso utilizado trata-se de algumas espécies da caatinga. 
Ainda acerca da discussão sobre a problemática da lenha como fonte energética para as indústrias da cal, verificou qual a origem da referida fonte de energia. Com isso, constatou-se na (Figura 5) que $80 \%$ desses recursos naturais são provenientes dos assentamentos localizados no entorno do Distrito de Soledade.

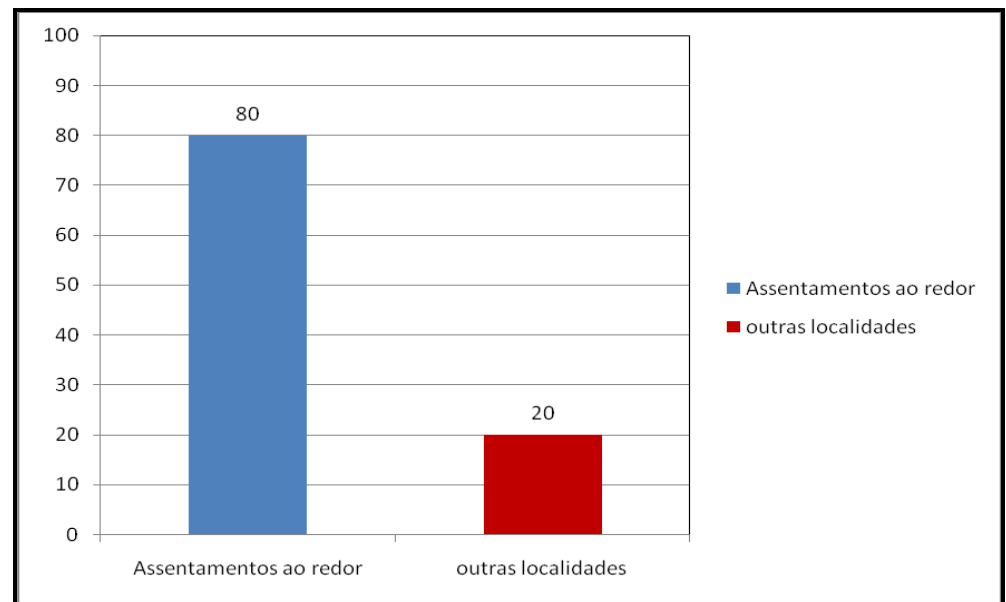

Figura 5: Local de origem da principal fonte energética, a lenha, 2009.

Fonte: dados da pesquisa.

Para efeito de melhor identificar os aspectos e impactos ambientais das Indústrias da cal em Soledade, faz se necessário mencionar o processo produtivo dessas industriais, conforme ilustra a Figura 6, referente ao fluxograma da produção da cal.

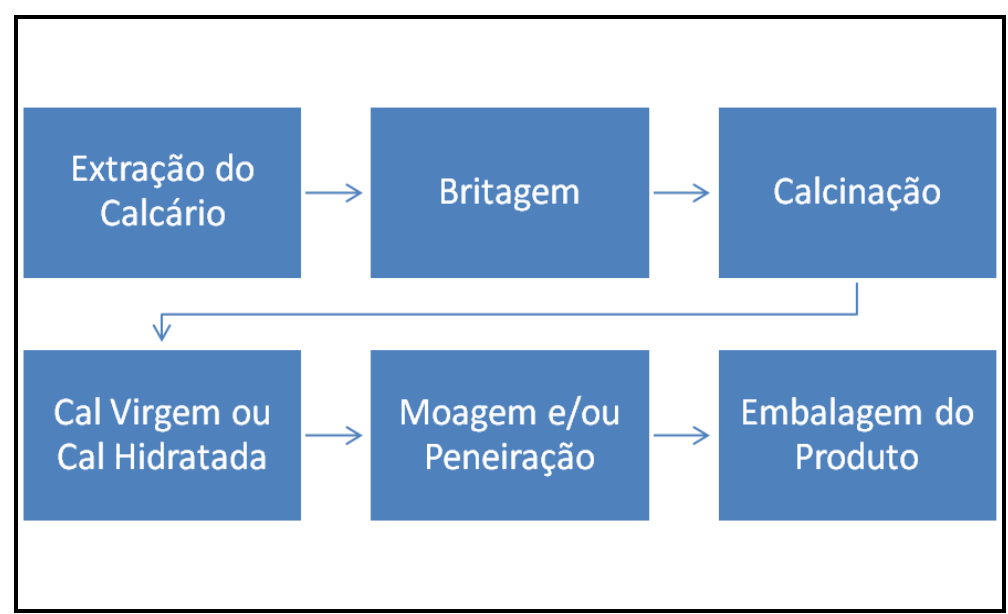

Figura 6: Fluxograma da produção da cal, 2009.

Fonte: Jorge Luis de Oliveira Pinto Filho.

Inicialmente, percebe-se que após a extração e transporte do calcário até o local da queima, essa matéria-prima passa por uma etapa de acomodamento no interior do forno. Na etapa de acomodamento, as pedras de calcário são empilhadas uma sobre as outras, debaixo para cima, sem que haja a utilização de argamassas para a estabilidade e fixação nessa estrutura.

Em seguida, à medida que as pedras vão sendo empilhadas, espaços vazios são deixados para permitir um maior contato da pedra com o fogo. Vale salientar, que com aumento do empilhamento os espaços vazios vão sendo reduzidos, até desaparecerem totalmente, e as últimas camadas de pedras são colocadas passando do limite do forno, formando, assim, uma espécie de 
cone revestido, com o objetivo de evitar a perda excessiva de calor, como pode ser observado na Figura 7.

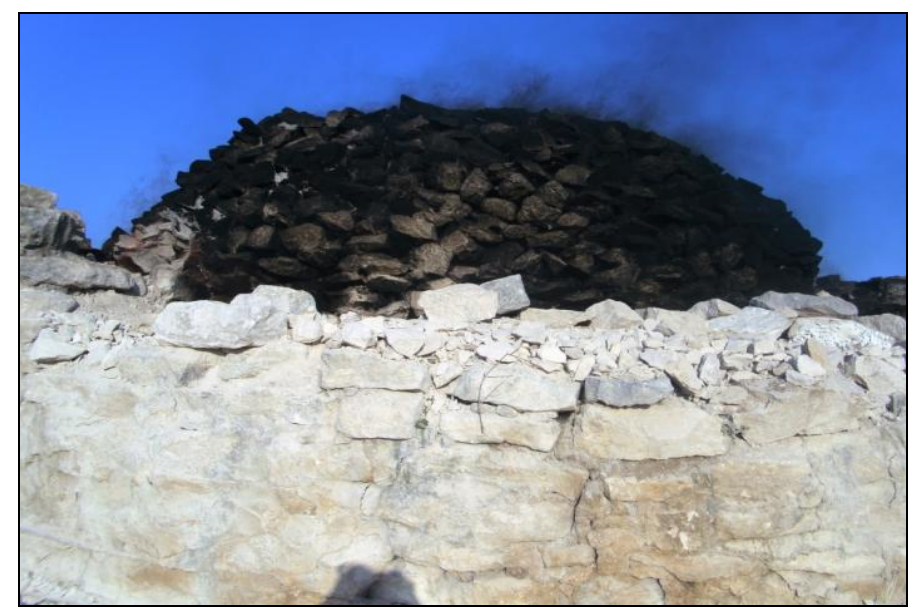

Figura 7: Vista de cima do forno no momento da queima da rocha de calcário, 2009.

Fonte: dados da pesquisa.

Cabe mencionar que esse processo da queima da pedra de calcário é denominado de calcinação, onde o calcário é queimado durante um período de três dias e duas noites. Nesse espaço de tempo, as jornadas de trabalho são divididas em dois turnos. O primeiro, com início às 5:00 horas da manhã e encerrado às 17:00 horas da tarde e segundo turno, com início às 17:00 horas da tarde e encerramento às 5:00 horas da manhã.

Com isso, os funcionários escalados para essa etapa do processo produtivo da cal têm a função de manter o forno com a sua capacidade máxima de temperatura, pelo fornecimento de lenha na boca no forno, como pode ser ilustrado na Figura 8.

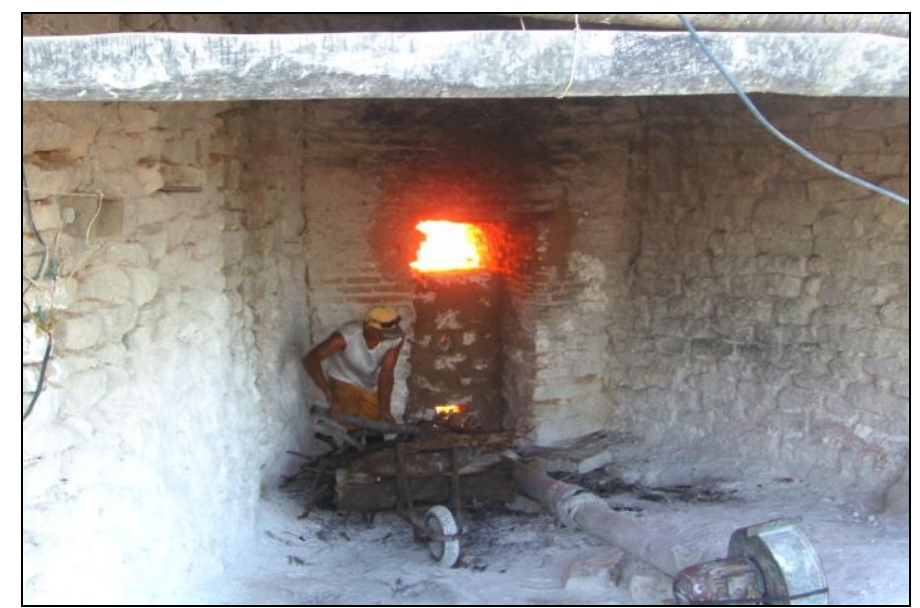

Figura 8: Fornecimento de lenha na boca do forno para queima da pedra de calcário, 2009.

Fonte: os autores.

Após a etapa de calcinação, a rocha calcária transforma-se em um elemento denominado de cal virgem, que ao ser retirado do forno, de forma manual, é levado até o local de catação, onde serão retiradas as pedras que não conseguiram queimar corretamente (Figura 9). 


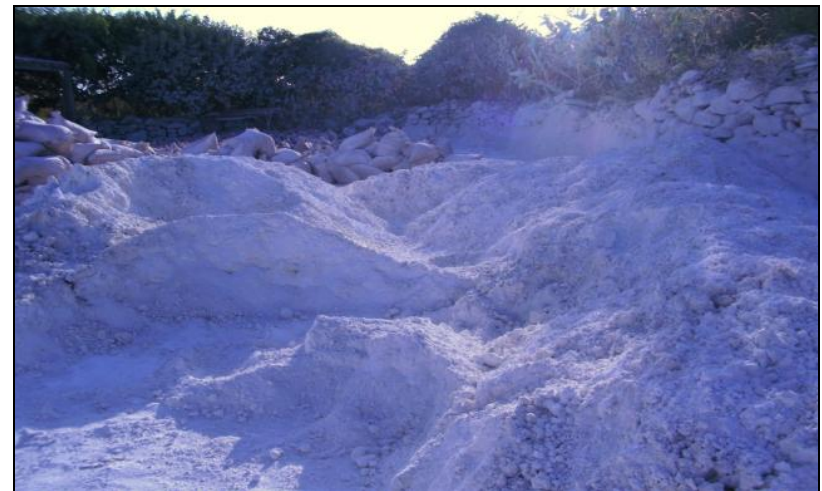

Figura 9: Cal após ser retirada do forno no local de catação, 2009.

Fonte: Luanna Lívia de Sousa Gurgel.

Por conseguinte, inicia-se a etapa de moagem ou peneiração, que se caracteriza pela enorme geração de poeira. Vale mencionar, que essa poeira constitui um potencial risco tanto a saúde dos trabalhadores e da população ao entorno das indústrias, quanto ao ambiente, pelo empoeiramento de espécies da vegetação nativa (Figura 10).

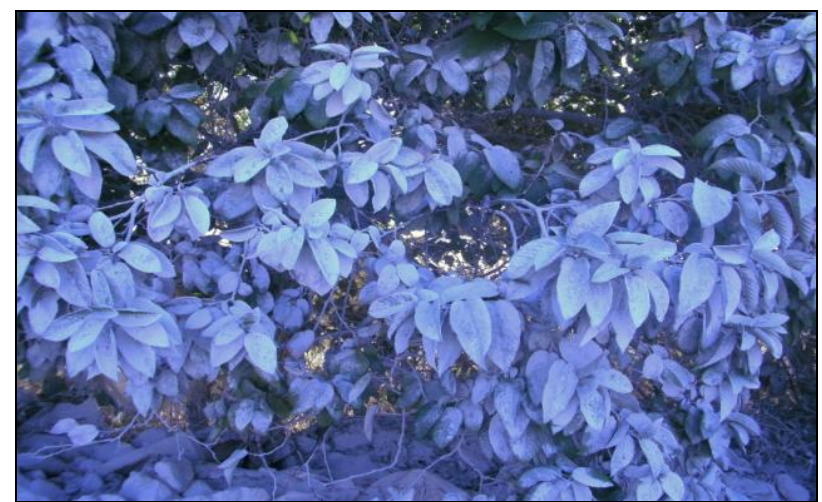

Figura 10: Poeira localizada sobre a vegetação.

Fonte: os autores.

Após, a etapa de moagem ou peneiração, ocorre o início da etapa de embalagem do produto final (Figura 11). Cabe destacar, que os produtos são apresentados e embalados em sacos de $60 \mathrm{~kg}$ e de $25 \mathrm{~kg}$. No entanto, é importante mencionar que esses produtos são apresentados no mercado, na maioria das vezes, a granel, ou seja, sem qualquer tipo de embalagem.

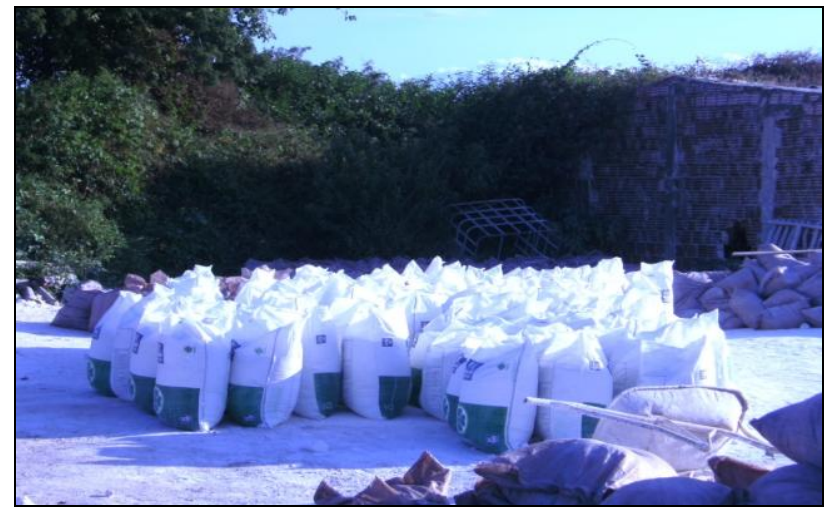

Figura 11: Embalagem do produto final, 2009.

Fonte: os autores. 
No que diz respeito ao tipo de cal produzida pelas indústrias do Distrito de Soledade constatam-se dois tipos principais, que são a cal virgem e a hidratada. Com o percentual de $(69,5 \%)$ os produtores afirmaram fabricar a cal virgem, alegando que esse tipo de produto vem a ser o mais fácil de produzir. Ainda em relação ao tipo de cal produzido, com um percentual de $(26,1 \%)$, os produtores produzem a cal hidratada. Esse tipo de produto recebe um tratamento diferenciado dos demais, pois a cal ao sair do forno, ocorre o adicionamento de água, sendo, em seguida, direcionado para a etapa de peneiração, para ser embalado. (Figura 12).

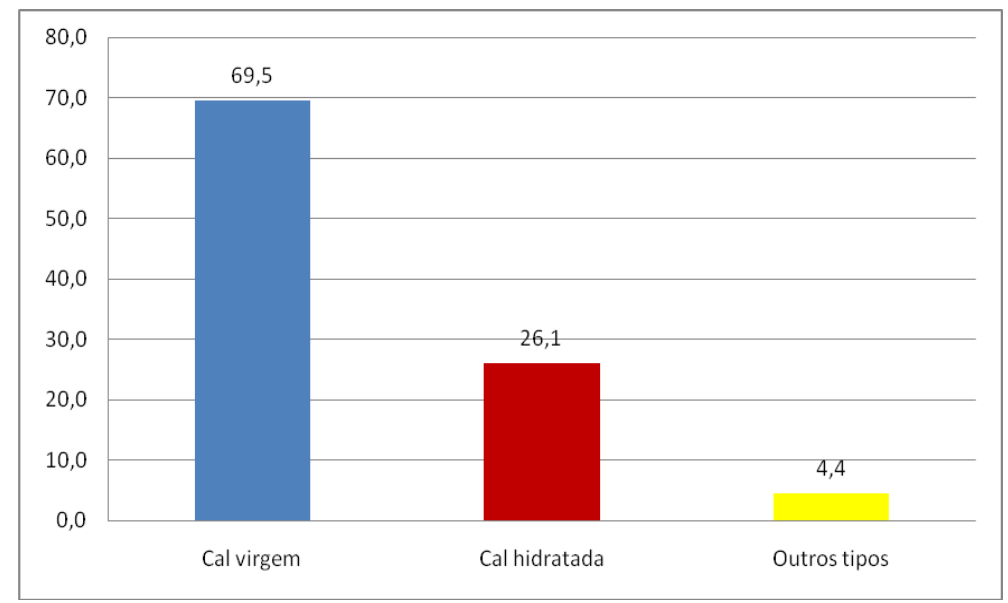

Figura 12: Tipos de cal produzidos no Distrito de Soledade, 2009.

Fonte: dados da pesquisa.

Ao investigar acerca dos resíduos sólidos gerados no processo produtivo da cal, verificou-se que $80 \%$ dos produtores questionados apontaram que não geram nenhum tipo de resíduo e, apenas $20 \%$ afirmaram gerar algum tipo de resíduo (Figura 12).

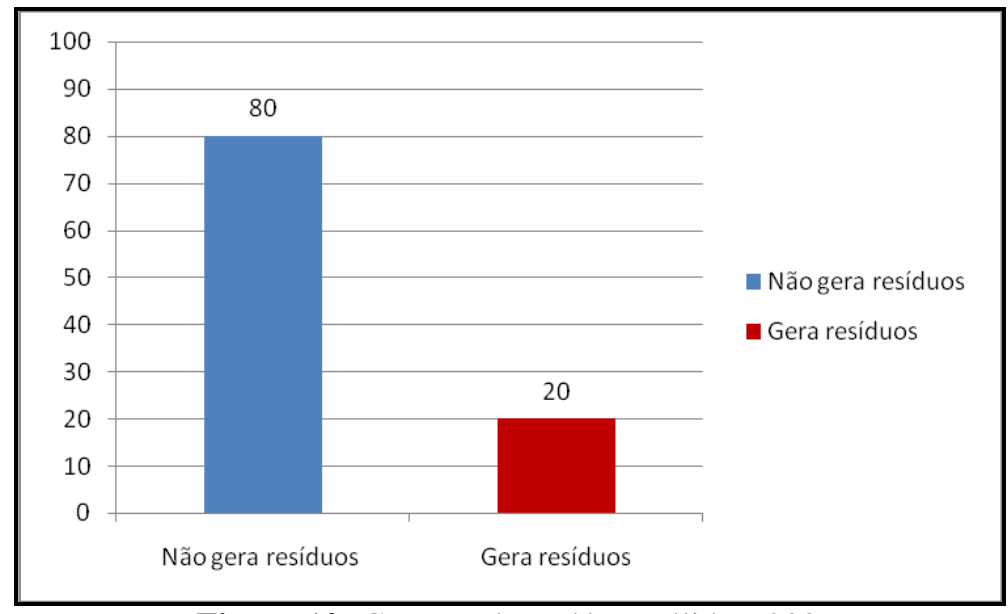

Figura 12: Geração de resíduos sólidos, 2009.

Fonte: os autores.

No entanto, constatou-se nos locais próximos das instalações das indústrias, o depósito de rejeito da produção dessa atividade (Figura 13). Entre a variedade desses resíduos detectados, podese elencar, as cinzas geradas pela queima da lenha e pequenos pedaços de calcário que não conseguiram passar pelo processo de calcinação. 


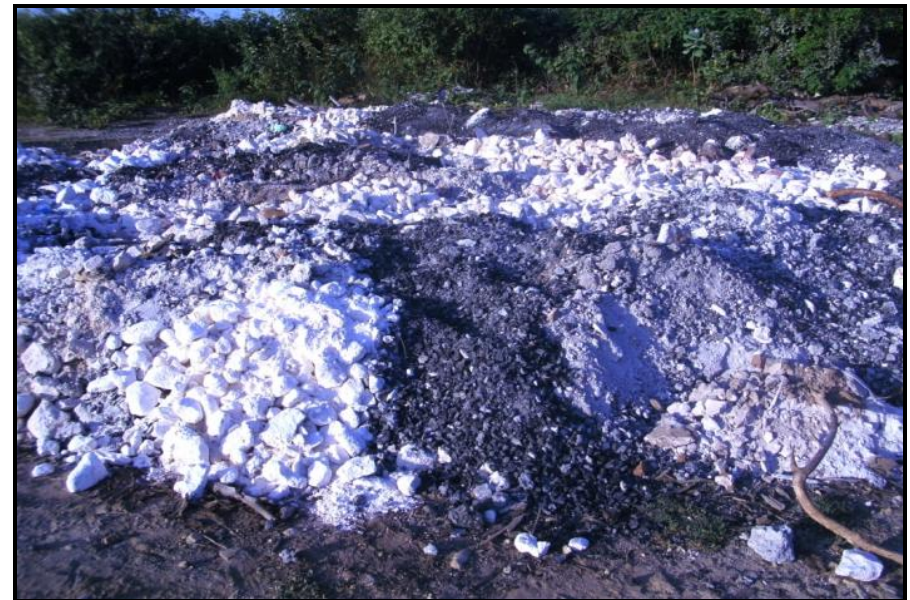

Figura 13: Disposição do rejeito da produção da cal, 2009.

Fonte: os autores.

É importante mencionar, a investigação realizada no questionário, no que diz respeito à relação dos produtores com os demais usuários do recurso natural calcário. Com isso, constatou-se que $100 \%$ dos questionados mencionaram que nunca tiveram nenhum tipo de problema com as indústrias vizinhas em relação à quantidade de calcário a ser captado, uma vez que cada produtor tem o seu local certo de extração do calcário.

Mesmo os produtores não tendo conflitos entre si, de acordo com as informações descritas acima, percebe-se que podem no futuro terem problemas com outros usuários desse recurso mineral, já que 33,3\% (figura 14) dos empresários do ramo da cal confirmaram que realizam extração da pedra de calcário de locais localizados próximos a Área de Preservação Permanente APP do Sítio Arqueológico do Lajedo de Soledade.

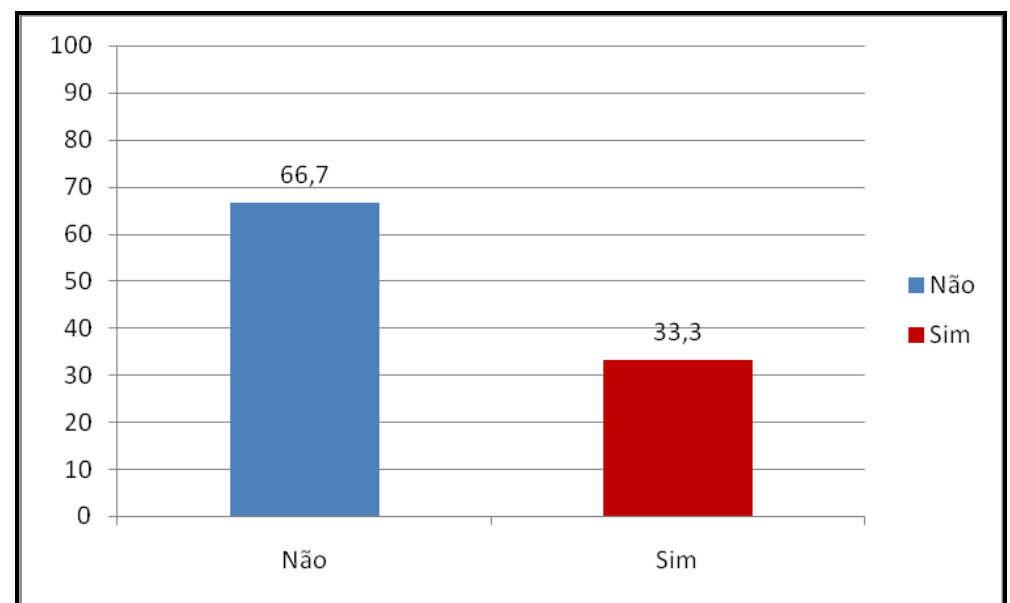

Figura 14: Área de extração do calcário próxima da área de preservação. Fonte: Permanente do Lajedo de Soledade, 2009.

Para finalizar a discussão sobre o perfil das indústrias da cal, investigou-se a situação dos trabalhadores dessa atividade econômica. Para isso, questionou se as indústrias realizam algum tipo de treinamento com os seus funcionários com as temáticas de segurança, saúde e meio ambiente. Constatou assim que 100\% dos responsáveis pelas indústrias mencionaram não realizar nenhum tipo de treinamento nas áreas descritas anteriormente.

A situação fica mais preocupante em relação aos cuidados das indústrias da cal com seus funcionários, quando se apura o percentual dos funcionários que utilizam os Equipamentos de Proteção Individual - EPIs representado na Figura 15 por apenas $(16,7 \%)$. 


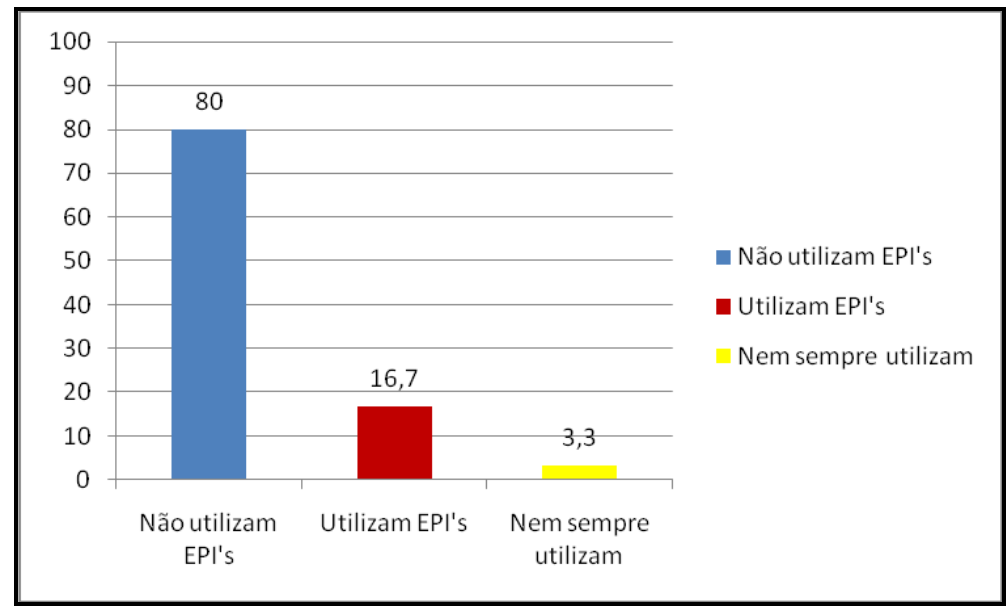

Figura 15: Uso de equipamentos de proteção individual, 2009.

Fonte: os autores.

Ainda, evidenciando a questão das condições dos trabalhadores das Indústrias da Cal, ao indagar os responsáveis das referidas unidades econômicas a respeito da estrutura disponível para o bem-estar dos funcionários, $100 \%$ dos responsáveis questionados relataram a não existência de banheiros, bebedouros ou refeitórios nas instalações das indústrias.

\section{CONSIDERAÇÕES FINAIS}

É notório que a atividade caieira no Distrito de Soledade é de grande importância para economia local e regional. Entretanto, tal atividade tem trazido alguns impactos de ordem socioambiental na comunidade.

As indústrias que compõem o setor da atividade da cal apresentam um perfil de microempresa, já que possuem até 19 empregados.

Apontam-se também características homogêneas das indústrias da cal, em termos de volume de produção, das técnicas utilizadas, dos produtos produzidos, das condições de trabalho e do destino final, entre outros. Com relação às condições de trabalho dos empregados da atividade da cal são precárias, já que a maioria dos funcionários não utiliza equipamento de proteção individual.

É importante que os produtores do setor vejam, nas iniciativas ambientais, não apenas a obrigação em estar em conformidade com a legislação e exigências dos órgãos governamentais, mas também a possibilidade de reduzir custos, aumentar sua produtividade e, como consequência, trazer desenvolvimento para a comunidade da qual faz parte. $O$ setor da atividade caieira necessita de estímulos à pesquisa e ao desenvolvimento de novas técnicas de produção, visando inovações tecnológicas dos produtos, bem como a otimização do seu desempenho ambiental.

A atividade da caieira causa diversos impactos ambientais, tais como degradação da área, devido à extração do calcário; supressão vegetal, para fornecimento de lenha como fonte energética e poluição atmosférica, pela liberação de partículas sólidas dos fornos das caieiras.

Portanto, a implementação de Sistema de Gestão Ambiental nas Indústrias da Cal pode-se concretizar como um mecanismo de amenização da problemática da degradação ambiental, bem como melhoria da qualidade do produto no Município de Apodi - RN. Além dos mais, faz necessário adotar políticas públicas sobre manejo florestal da caatinga, com a finalidade de rever o cenário de possibilidade de Área Susceptível à Desertificação no distrito de Soledade, no Município de Apodi - RN. 


\section{REFERÊNCIAS}

ABNT - Associação Brasileira de Normas Técnicas. NBR ISO 14.001 Sistemas de Gestão Ambiental(2004) - Requisitos com orientações para uso. Rio de Janeiro. ABNT, 2004.

Almeida, I.T. de. A poluição atmosférica por material particulado na mineração a céu aberto. (1999) Dissertação de mestrado, escola Politécnica da Universidade de São Paulo. São Paulo. Recuperado em 15 junho 2009, de: www.scielo.br >

Barbosa Filho, A.N.(2001). Segurança do trabalho e gestão ambiental. São Paulo: Atlas.

Braga, B.et al. (2005) Introdução à engenharia ambiental. (2ª Ed.) São Paulo: Pearson Prentice Hall.

.Brasil.(1976) Lei de $n^{\circ} 6.367$, de 19 de outubro.

.Brasil. (1981) Lei Federal no 6.938, de 31 de agosto.

Brito Guerra, V. de. (1985) Histórias e vultos de minha terra. Série C, volume cccxiii. Apodi-RN. Coleção Mossoroense.

Derisio, J.C.(1992) Introdução ao controle de poluição ambiental. (1 ${ }^{\mathrm{a}}$ Edição). Cetesb, São Paulo, Brasil.

Dias, R.(2006) Gestão ambiental: responsabilidade social e sustentabilidade. São Paulo: Atlas.

Gil, A.C.(2006) Como elaborar projetos de pesquisa. (4ª ed.) São Paulo: Atlas.

Idema - Instituto de Desenvolvimento Econômico e Meio Ambiente do Rio Grande do Norte(2003), Diretoria Técnica Administrativa. Perfil do seu município: aspectos geoambientais e socioeconômico. Relatório.

Jucá, José F. T. (2002). Destinação final dos resíduos sólidos no Brasil: situação atual e perspectivas. In: Anais do Silubesa - Simpósio Luso Brasileiro de Engenharia Sanitária e Ambiental, 10. Braga, Portugal.

La Rovere, E.L.(2001) Instrumentos de planejamento e gestão ambiental para a Amazônia, cerrado e pantanal: demandas e propostas: metodologia de avaliação de impacto ambiental. (Série meio ambiente em debate). Brasília: Ed. IBAMA.

Lora, E.E.S. (2002) Prevenção e controle da poluição nos setores energético, industrial e transporte. ( $2^{\mathrm{a}}$ Ed.) Rio de Janeiro: Interciência.

Marques, J.R. (2005) Meio ambiente urbano. Rio de Janeiro: Forense Universitária.

Minayo, M.C. de S. et al. Qualidade de vida e saúde: um debate necessário. Revista Ciência \& Saúde Coletiva. 5(1) Rio de Janeiro, 2000. Recuperado em 13 abril 2009, de: 〈www.scielo.com > 
Moura, H.J.T. de. (2003) O uso das metodologias de avaliação de impacto ambiental em estudos realizados no Ceará. Fortaleza, Ceará.

Philippi JR, A., Alves, A.C.(2005) Curso interdisciplinar de direito ambiental. Barueri, SP: Manole.

Sànchez, L.E.(2008) Avaliação de impacto ambiental: conceitos e métodos. São Paulo: Oficina de Textos.

Santana, V.S.(2006) Saúde do trabalhador no Brasil: pesquisa na pós graduação. Revista Saúde Pública. Recuperado em 14 abril 2009, de: 〈www.scielo.br>.

Silva, C.P. et al.(2007) Percepção de caieiros quanto às consequiências do trabalho no processo saúde-doença. Revista de Saúde Pública. 41(5):858-60. Recuperado em 10 junho 2009, de: <www.scielo.br>.

Sousa, W.L. de.(2000) Impacto ambiental de hidrelétricas: uma análise comparativa de duas abordagens. Tese de Mestrado de Ciências em Planejamento Energético. Rio de Janeiro, RJ Brasil. Recuperado em 22 abril 2009, de: 〈www.unicamp.br> Vianna, F.M. de A.(2006) Participação pública em programas ambientais: um estudo em área suscetível à desertificação no Estado do Rio Grande do Norte. Natal/RN. Tese de Mestrado UFRN. Recuperado em 3 junho 2009, de: 〈www.unicamp.br >.

Data do recebimento do artigo: $24 / 09 / 10$

Data do aceite de publicação: 20/02/2012 